\title{
Indian monsoon variability in relation to Regional Pressure Index
}

\author{
S S DUGAM and S B KAKADE \\ Indian Institute of Tropical Meteorology, Pune 411 008, India.
}

\begin{abstract}
In this paper Regional Pressure Index (RPI) over the Indian region $\left(20^{\circ} \mathrm{N}-40^{\circ} \mathrm{N}\right.$ and $\left.70^{\circ} \mathrm{E}-85^{\circ} \mathrm{E}\right)$ has been constructed for 101 years (1899-1999) on a monthly scale. The relationship of these indices was carried out with the Indian Summer Monsoon Rainfall (June-September) (ISMR) over the various homogeneous regions, for all the time scales. From the analysis it has been seen that RPI in the month of May is significantly associated with ISMR over various regions on all the scales. The relationship is statistically significant at $1 \%$ level. The study reveals that RPI in the month of May and January will be a new precursor for the long range forecasting of ISMR on the smaller spatial scale. On the decadal and climatological scale, winter and spring time RPI show a significant inverse relationship with the rainfall over the regions Peninsular India (PI) and North West India (NWI), while the association is direct with Central North East India (CNEI) and North East India (NEI). The relationship is significant at 0.1 and $1 \%$ level respectively.
\end{abstract}

\section{Introduction}

Inter-annual variation of Indian summer monsoon rainfall generates profound socio-economic impact on many spheres of national activities. Therefore there has always been a great demand for the Long Range Forecasting (LRF) of monsoon rainfall over India. From the time of Blanford (1884) up to the recent period, a large number of researchers viz., Walker (1923, 1924); Thapliyal (1982); Gowariker et al (1989, 91); Goswami and Srividya (1996) have made attempts to search the new parameters and have developed models for LRF of seasonal rainfall over India. But as there is a great demand for long range forecast of monsoon rainfall on smaller spatial and temporal scales, there is a need to search for new predictors which can be used on smaller spatial and temporal scales, for developing the LRF models.

In the past, many indices have been constructed on various meteorological parameters for studying the tropical and extra-tropical interaction in both the hemispheres and also for the purpose of regional weather forecasting (Sikka 1980; Joseph et al 1981; Chen 1982; Shukla and Paolino 1983; Webster and Yany 1992; Parthasarathy et al 1988; Chattopadhyay et al 1994; Singh D et al 1996; Harzallah and Sadourry 1997; Dugam et al 1997; Dugam and Kakade 1999 and Kakade and Dugam 2000 etc.). Most of these studies are related to the zonal index cycle in Northern Hemisphere $(\mathrm{NH})$ and Southern Hemisphere (SH). But in spite of these zonal indices the Regional Pressure Index (RPI) may play quite a significant role in weather events like precipitation, cyclone activity and the passage of trough and ridge over the region.

In order to see the meridional variation of the pressure gradient anomalies over the central north western Indian region and its impact on ISMR, we have constructed the pressure gradient anomaly series on a monthly scale. For this we have chosen the region between $20^{\circ} \mathrm{N}-40^{\circ} \mathrm{N}$ and $70^{\circ} \mathrm{E}-85^{\circ} \mathrm{E}$. This region has been chosen because the heat low and dynamic low (monsoon trough zone) over this region, plays a crucial role in the variability of the monsoon and also because this region is very much affected by extra tropical disturbances like western disturbances and intrusion of mid latitude

Keywords. Regional Pressure Index; Indian monsoon rainfall.

Proc. Indian Acad. Sci. (Earth Planet. Sci.), 112, No. 4, December 2003, pp. 521-527

(C) Printed in India. 

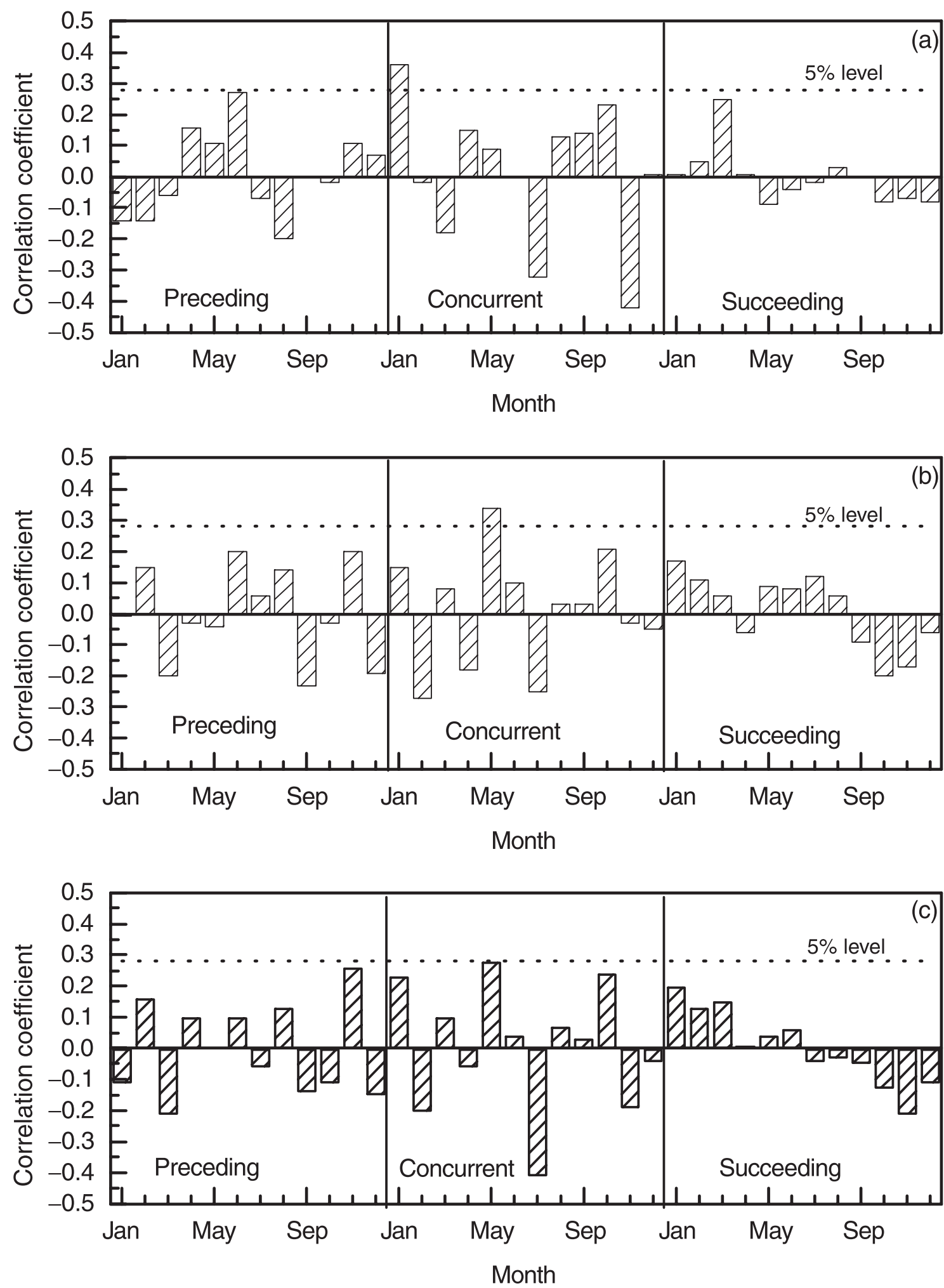

Figure 1. Relationship between normalized monsoon rainfall over (a) Central north-east India, (b) North-west India and (c) Homogeneous India and monthly Regional Pressure Index during preceding, concurrent and succeeding years for (1951-1999).

trough which is known to affect the Indian monsoon adversely.

For the construction of these indices we have taken monthly mean sea level pressure data from the web site http:// tao.atmos.Washington. edu/data-sets/. Monthly mean sea level pressure data across $40^{\circ} \mathrm{N}$ and $20^{\circ} \mathrm{N}$, along $70^{\circ} \mathrm{E}, 75^{\circ} \mathrm{E}, 80^{\circ} \mathrm{E}$ and $85^{\circ} \mathrm{E}$, have been obtained for the $1899-2001$ 

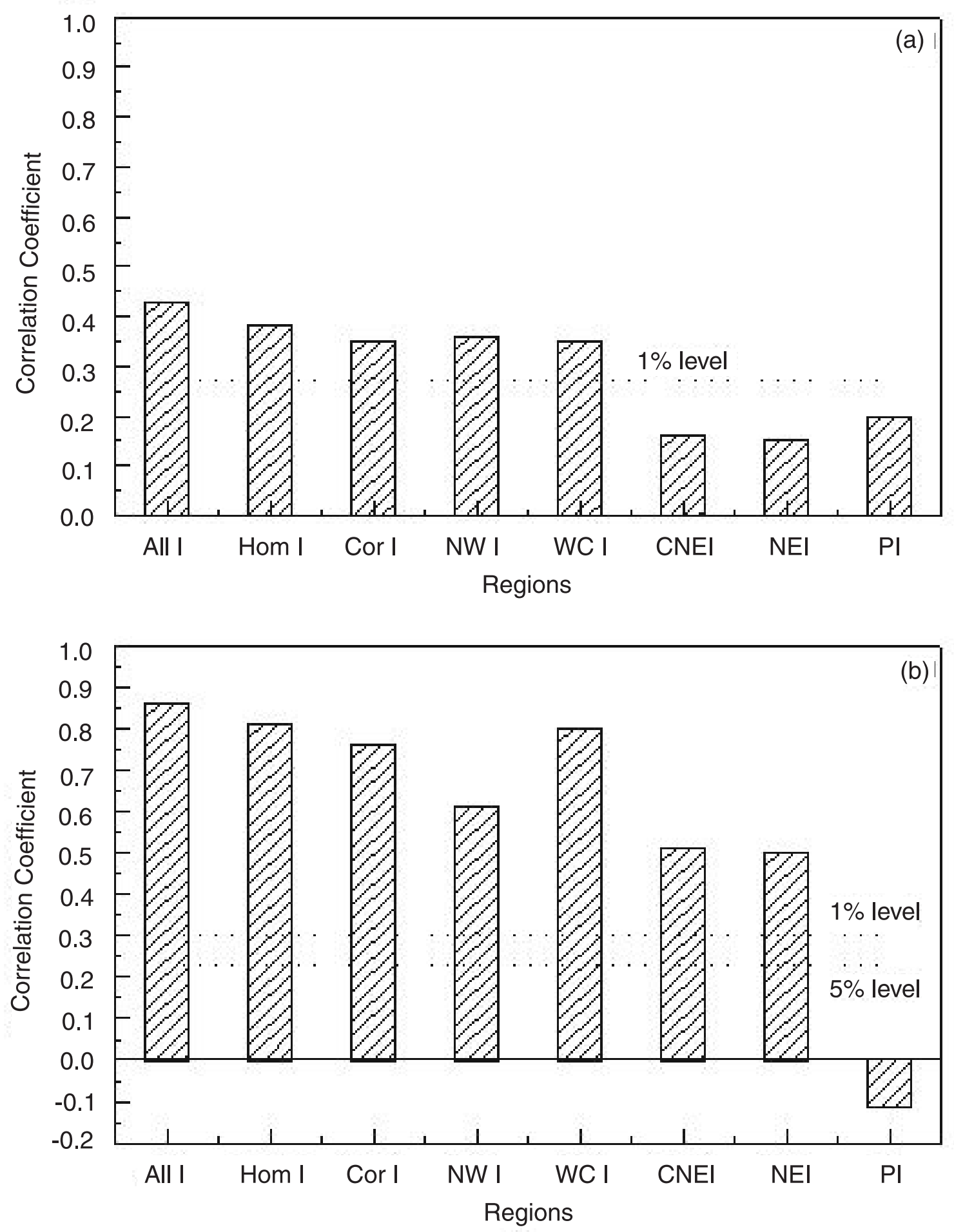

Figure 2. Correlation coefficients of monsoon rainfall over different homogeneous regions of India and Regional Pressure Index in the month of May for 1900-1999, on (a) decadal scale and (b) climatological scale.

period. The pressure gradient between $40^{\circ} \mathrm{N}$ and $20^{\circ} \mathrm{N}$ is then calculated for each month along the above mentioned four longitudes. The average of four series along longitudes, for each month, gives the monthly average pressure gra- dient over the Indian region. The anomaly from the annual mean is then normalized by annual standard deviation and the monthly series so obtained is termed as regional pressure index (RPI). 

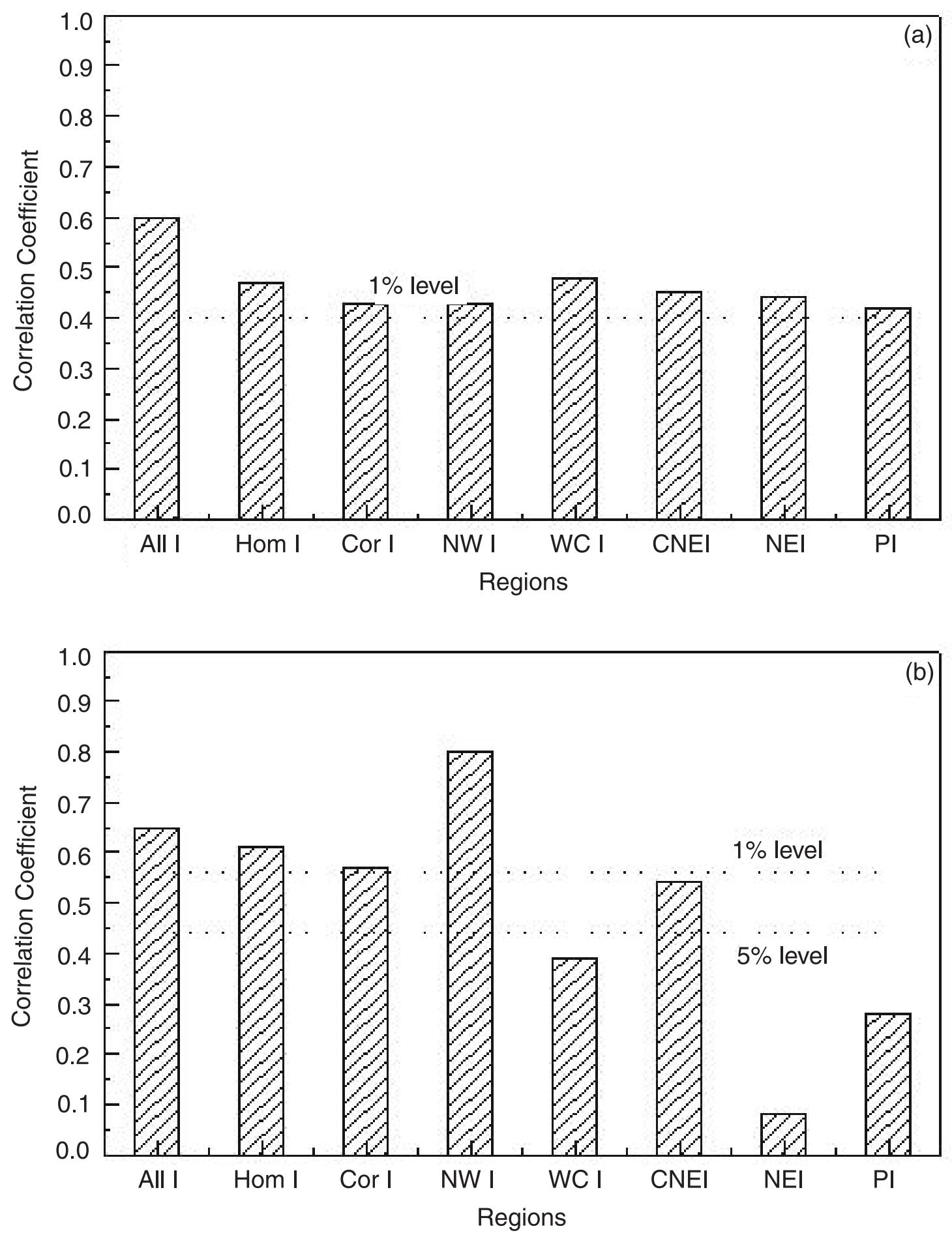

Figure 3. Correlation coefficients of monsoon rainfall over different homogeneous regions of India and Regional Pressure Index in the month of May for 1951-1999, on (a) decadal scale and (b) climatological scale.

\section{Data and methodology}

As mentioned earlier, the RPI series are prepared and used for the analysis. The seasonal Indian Summer Monsoon Rainfall (ISMR) (JuneSeptember) series for the different homogenous regions for the period 1899-1999 have been taken from Parthasarathy (1993, 1994). The correlation technique is used for the analysis.

\section{Discussion}

The analysis of Regional Pressure Index (RPI) with the ISMR has been carried out on the various time 

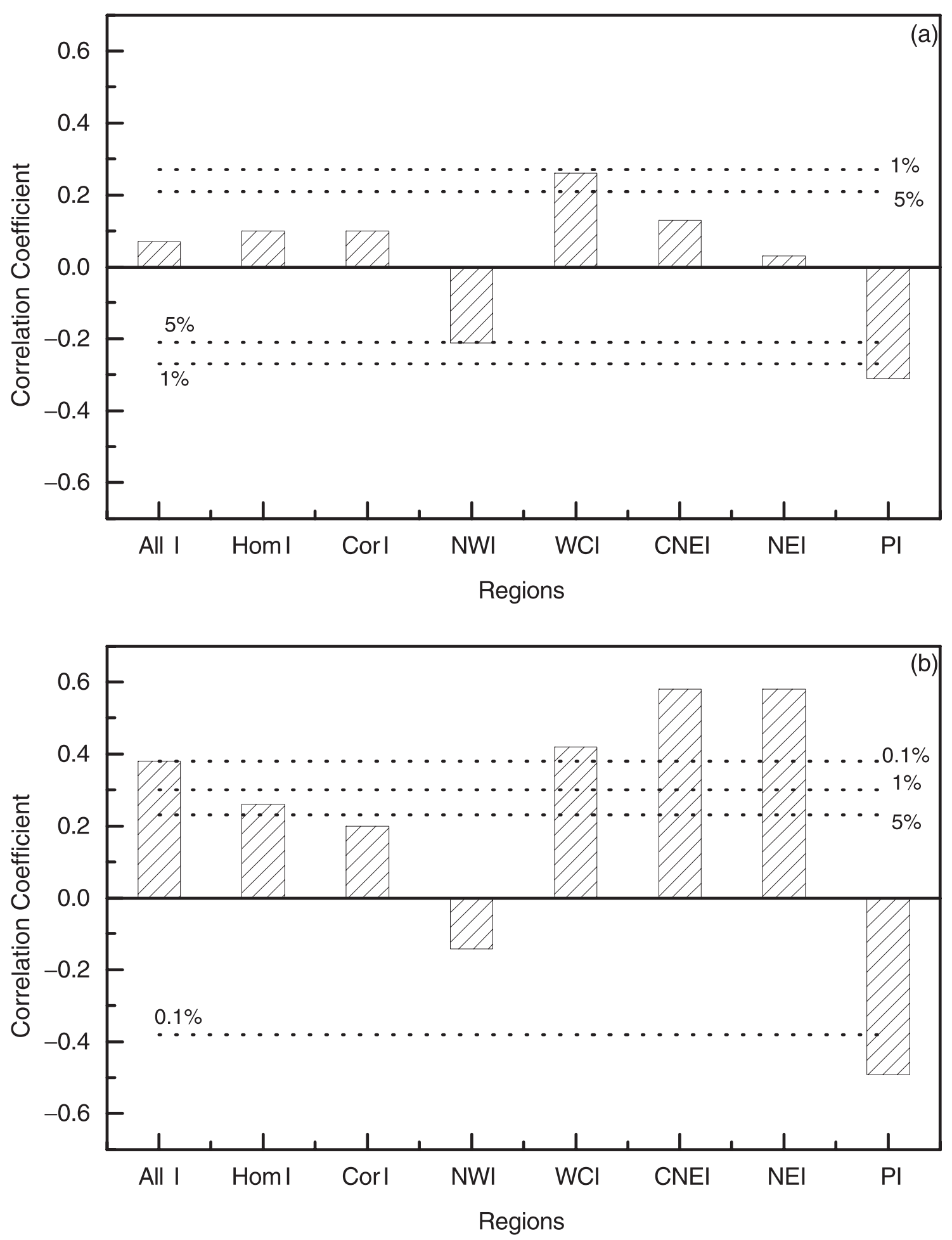

Figure 4. Correlation coefficients of monsoon rainfall over different homogeneous regions of India and Regional Pressure Index in the winter season for 1900-1999, on (a) decadal scale and (b) climatological scale.

scales i.e. monthly, seasonal, decadal and climatological scales. The analysis is carried out with data sets of different periods. Firstly the analysis is carried out for the period 1899-1999 and secondly for the recent 50 years i.e., 1951-1999.

\subsection{Monthly scale analysis of RPI and ISMR}

The relationship between RPI and ISMR, on the monthly scale, does not show the statistically significant relationship during the 101 year period 
(1899-1999) but during the recent fifty year period (1951-1999) the relationship is significant with Central North East India (CNEI), North West India (NWI) and all India rainfall (figure 1). From the analysis it is seen that RPI in the month of January and May is showing a significant (5\% level) positive association with CNEI and NWI rainfall respectively. While the relationship with all India rainfall is significant at 5\% level in the month of May. This relationship may be used as a precursor for the LRF of monsoon rainfall over these regions.

The relationship between ISMR over different homogeneous regions of India and RPI in the month of May, on the decadal and climatological scale, for the 100 year period (1900-1999) and the recent fifty year period (1951-1999) is shown in figure 2 and figure 3 respectively. From the analysis it is observed that for the 100 year period almost all the regions except PI, on the climatological scale, are showing significant relationship with RPI (1\% level). For the recent 50 year period, RPI in the month of May, on decadal scale, is showing significant relationship ( $1 \%$ level) with ISMR over all homogeneous regions of India.

\subsection{Seasonal scale}

The relationship between RPI and ISMR over homogeneous regions is carried out on the seasonal scale. The analysis is carried out for all the standard seasons viz., winter (December-JanuaryFebruary), spring (March-April-May), summer (June-July-August) and autumn (SeptemberOctober-November). On the interannual scale it is seen that there is no significant relationship between them. But on the climatological scale it is seen that RPI in the winter season shows a significant $(0.1 \%$ level $)$ direct relationship with ISMR over regions all over India, West Central India (WCI), Central North East India (CNEI), and North East India (NEI). It shows a negative association with Peninsular India (PI) (figure 4). Except NWI, WCI and PI no other regions show a significant relationship with RPI, on the decadal scale. A similar result is observed for the spring season. Other seasons do not show such a relationship.

\section{Conclusions}

The following conclusions are drawn from the above study:

- In general it is observed that the long-term variability in Indian summer monsoon rainfall on various regions is very much related to the pressure gradient anomaly over the north western Asian region.
- The RPI in the month of January and May could be used as a precursor for the long range forecasting of Indian summer monsoon rainfall.

- The winter and spring time RPI can be used as a signal for the long-term prediction of ISMR over the various homogeneous regions of India.

Physical explanation for the relationship between RPI with ISMR could be explained through the tropical-extra topical interactive mechanism. The effect of mid-latitude disturbances like western disturbances (WDs), low and high index phase cycles cause cyclonic and anticyclonic features over the northern most part of Indian regions, which subsequently affect the upper tropospheric thermal structure (Verma 1980a; Verma and Sikka 1980b) and also affect the meridional pressure gradient over the region. This change in meridional pressure gradient affects the meridional transport of moisture flux over the Indian region which ultimately affects the monsoon rainfall activity over the Indian sub-continent.

\section{Acknowledgement}

The authors are grateful to the Director, I.I.T.M. and DST for providing necessary facilities for completing this study, and to Dr S S Singh, Head, forecasting research division for his encouragement and valuable suggestions.

\section{References}

Blanford H F 1884 On the connection of the Himalayan snow with dry winds and seasons of droughts in India; Proc. R. Soc. London 37 3-22

Chattopadhyay J, Bhatla R and Prakash O 1994 Zonal circulation indices, $500 \mathrm{hPa}$ April ridge position along $75^{\circ}$ East and Indian summer monsoon rainfall statistical relationship; Theoretical Applied Climatology 50 35-43

Chen W Y 1982 Assessment of southern oscillation sea level pressure indices; Mon. Weather Rev. 110 800-807

Dugam S S, Kakade S B and Verma R K, 1997 Interannual and long-term variability in North Atlantic Oscillation and Indian summer monsoon rainfall; Theoretical and Applied Climatology 58 1-2, 21-29

Dugam S S and Kakade S B 1999 Interactive-mechanism between ENSO and NAO and its relationship with Indian summer monsoon variability; Proc. National Symposium TROPMET-99 Chennai Feb. 16-19 53-58

Goswami P and Srividya 1996 A novel neural network design for long range prediction of rainfall pattern; Curr. Sci. $70447-457$

Gowariker V, Thapliyal V, Sarkar R P, Mandal G S and Sikka D R 1989 Parametric and power regression models: New approach for long range forecasting of monsoon rainfall in India; Mausam 40 115-122

Gowariker V, Thapliyal V, Kulsheshtra S M, Mandal G S, Sen Roy N and Sikka D R 1991 A power regression model for long range forecast of southwest monsoon rainfall over India; Mausam 42 125-130 
Harzallah A and Sadourry R 1997 Observed lead-lag relationships between Indian summer monsoon and some meteorological variables; Climate Dyn. 13 635-648

Joseph P V, Mukhopadhyaya R K, Dixit M V and Vaidya D V 1981 Meridional wind index for long range forecasting of Indian summer monsoon rainfall; Mausam 32 31-34

Kakade S B and Dugam S S 2000 Simultaneous effect of $\mathrm{NAO}$ and $\mathrm{SO}$ on the monsoon activity over India; Geophys. Res. Lett. 27 3501-3504

Parthasarathy B, Diaz H F and Eischel J K 1988 Prediction of all India summer monsoon rainfall with regional and large-scale parameters; J. Geophys. Res. 93 5341-5350

Parthasarathy B, Rupakumar K and Munot A 1993 Homogeneous Indian monsoon rainfall: variability and prediction; Proc. Indian Acad. Sci. (Earth Planet Science) 102 $121-155$

Parthasarathy B, Munot A and Kothawale D R 1994 AllIndia monthly and seasonal rainfall series 1887-1993; Theoretical and Applied Clmatology 49 217-224

Shukla J and Paolino D A 1983 The southern oscillation and long range forecasting of summer monsoon rainfall over India; Mon. Weather Rev. 111 1830-1837

Sikka D R 1980 Some aspects of the large scale fluctuations of summer monsoon rainfall over India in relation to fluctuations in the planetary and regional scale circulation parameters; Proc. Indian Acad. Sci. (Earth and Planetary Sciences) 89 179-195

Singh D, Goyal S, Bhadram C V V and Mandal G S 1996 Importance of meridional winds in forecasting subregional summer monsoon rainfall; Mausam 473 275-280

Thapliyal V 1982 Stochastic dynamic model for long range prediction of monsoon rainfall in Peninsular India; Mausam 33 399-404

Verma R K 1980a Importance of upper tropospheric thermal anomalies for long range forecasting of Indian summer monsoon activity; Mon. Weather Rev. 108 230-233

Verma R K and Sikka D R 1980b A study of anomalous thermal patterns during early summer season of 1979 over Afro-Asian region in relation to the large scale performance of monsoon rains over India; GARP Report: results of summer MONEX field phase research (Part A) 33 4450

Walker G T 1923 Correlation in seasonal variation of weather VIII: A preliminary study of world weather; Mem. India Met. Dept. 24 75-131

Walker G T 1924 Correlation in seasonal variation of weather IX: A further study of world weather; $\mathrm{Mem}$. India Met. Dept. 24 225-232

Webster P J and Yany S 1992 Monsoon and ENSO: Selectively interactive systems; $Q$. J. R. Meteor. Soc. 118 877-926 